\title{
Penerapan Model ARIMA-GARCH Untuk Memprediksi Harga Saham Bank BRI
}

\author{
Natasya Bella Yolandaa*, Nelson Nainggolana, Hanny A.H. Komaliga \\ aJurusan Matematika, FMIPA, Unsrat, Manado
}

KA TA KUNC I

ARIMA-GARCH

Harga Saham

Bank BRI

\begin{abstract}
A B S T R A K
Model time series yang dapat mengakomodasi sifat heteroskedastik adalah model ARCH atau GARCH. Penelitian ini bertujuan untuk menerapkan model ARIMA-GARCH dalam memprediksi harga saham bank BRI. Hasil penelitian menunjukkan bahwa pada harga saham bank BRI terdapat unsur heteroskedastik. Model terbaik yang didapat pada harga saham bank BRI yaitu ARIMA(2,1,1)-GARCH(2,2). Model tersebut memiliki nilai koefisien determinasi atau $R^{2}$ (R-squared) yaitu sebesar 0.99916 atau $99,91 \%$.

A B S T R A C T $A R C H$ or GARCH model. This study aims to apply and determine the ARIMA-GARCH models in predicting stock prices of bank BRI. The result of this research show that in bank BRI stock price there is heteroscedasticity element. The best model obtained in bank BRI stock price that is ARIMA $(2,1,1)-G A R C H(2,2)$. The model determination or $R^{2}(R$-squared) 0.99916 or $99.91 \%$
\end{abstract}

K E Y W O R D S

ARIMA-GARCH

Stock Price

Bank BRI
TERSEDIA ONLINE

01 Agustus 2017

1. Pendahuluan

Dalam beberapa tahun ini masalah perkembangan sektor finansial cenderung berfluktuasi secara cepat. Misalnya pada indeks harga saham yang biasanya memiliki variansi yang tidak konstan atau selalu berubah setiap waktu (heteroskedastik). Indeks harga saham merupakan informasi yang diperlukan masyarakat untuk mengetahui perkembangan pergerakan harga saham. Beberapa jenis eminten perbankan yang berada pada Indeks Harga Saham Gabungan (IHSG) antara lain BNI dan BRI.

Model runtun waktu yang dikembangkan oleh Box-Jenkins yaitu diantaranya, model Autoregressive (AR), Moving Average (MA), Autoregressive Moving Average (ARMA), dan model Autoregressive Integrated Moving Average (ARIMA). Model-model tersebut berdasarkan asumsi bahwa datanya stasioner dan variansinya tetap/konstan (homoskedastik). Model ARIMA variansi konstan telah diaplikasikan pada data penumpang pesawat terbang (Salmon, 2015) dan jumlah tindak kriminalitas Polresta Manado (Mendome, 2016). Pemodelan ARIMA tidak relevan jika dihadapkan pada data dengan variansinya yang tidak konstan (heteroskedastik). Untuk itu dibutuhkan model yang dapat digunakan untuk dihadapkan pada data dengan kondisi heteroskedastik yaitu model Autoregressive Conditional Heteroscedastic (ARCH) dan model Generalized Autoregressive Conditional Heteroscedastic (GARCH).

Model Autoregressive Conditional Heteroscedastic (ARCH) diperkenalkan oleh Engle (1982) yang merupakan suatu model time series yang dapat mengakomodasi sifat hetroskedastik. Proses ARCH adalah proses dengan rataan (mean) nol, tak berkorelasi, variansi bersyarat (conditional) pada waktu lampau tidak konstan, sedangkan variansi tak bersyarat (unconditional) adalah konstan. Kemudian Bollerslev (1986) mengembangkan model ARCH menjadi model Generelized Autoregressive Conditional Heteroscedastic (GACRH), (Bollerslev, 1986). Engle (1982) telah berhasil melakukan penelitian tentang perkiraan varians dari inflansi United Kingdom dengan menggunakan model Autoregressive Conditional Heteroscedastic $(A R C H)$.

Dari hasil penelitian Eliyawati, et al (2014) menerapkan model GARCH data harga saham LQ 45 menjadi tidak bersifat heteroskedastik hal ini menunjukkan bahwa model GARCH cocok untuk

*Corresponding author: Jurusan Matematika FMIPA UNSRAT, Jl. Kampus Unsrat, Manado, Indonesia 95115; Email address: natasyabellayolanda@gmail.com Published by FMIPA UNSRAT (2017) 
diterapkan dalam menganalisis data time series khususnya pada data keuangan contohnya indeks harga saham yang digunakan pada penelitian ini.

Berdasarkan uraian diatas, maka dalam penelitian ini akan dilakukan pengujian harga saham bank BRI periode 2014-2017. Sama seperti penelitian sebelumnya, model yang akan digunakan pada penelitian ini yaitu model ARCH atau GARCH.

\section{Material dan Metode}

\section{Waktu dan Tempat Penelitian}

Penelitian ini dilakukan pada bulan April 2017 sampai September 2017 di Laboratorium Komputer Dasar FMIPA Unsrat. Pada penelitian ini data yang digunakan yaitu data sekunder time series untuk data harga penutupan saham harian (closing price) bank BRI mulai periode 3 Januari 2014 sampai dengan 12 Mei 2017. Jumlah pengamatan yaitu 876 hari pengamatan dimana hari efektif perdagangan pada bursa saham yaitu 5 hari kerja dalam satu minggu (Senin-Jumat). Data bersumber dari website Yahoo Finance (https://finance.yahoo.com).

\section{Teknik Analisis data}

Teknik analisis yang digunakan dalam mengaplikasikan model GARCH pada penelitian ini menggunakan bantuan perangkat lunak komputer dengan urutan langkah sebagai berikut:

1. Uji stasioneritas data

a. Uji akar unit (Unit Root Test)

b. Correlogram ACF dan PACF

c. Proses diferensing

2. Indentifikasi model ARIMA

3. Estimasi model ARIMA

4. Uji diagnosis model ARIMA

5. Identifikasi efek ARCH atau GARCH (heteroskedastik)

6. Estimasi model ARCH atau GARCH

7. Evaluasi model ARIMA-GARCH

\section{Hasil dan Pembahasan}

Bank BRI memiliki pergerakan harga saham yang berfluktuatif (naik atau turun). Fluktuatif pada harga saham bank BRI dapat dilihat pada grafik berikut:

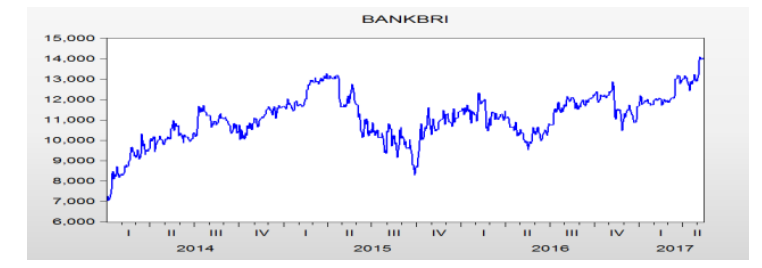

Gambar 1. Grafik Harga Saham BRI

Gambar 1 merupakan grafik harga penutupan (closing price) saham bank BRI yang diambil pada periode Januari 2014 sampai Mei 2017.

\section{Uji Stasioneritas}

Uji akar unit (Unit root test)

Hasil uji akar unit dapat dilihat berdasarkan uji hipotesis sebagai berikut:
$H_{0}$ : Bank BRI memiliki akar unit (data tidak stasioner)

$H_{1}$ : Bank BRI tidak memiliki akar unit (data stasioner)

$\alpha=0,05$

Berdasarkan hasil output nilai p-value $=0,0095<$ 0,05 , maka tolak $H_{0}$ artinya harga saham bank BRI tidak memiliki akar unit atau data sudah stasioner.

\section{Correlogram ACF dan PACF}

Setelah melakukan uji akar unit dimana data sudah stasioner, selanjutnya dapat dilihat dari correlogram ACF dan PACF. Berdasarkan pada uji akar unit, telah diketahui bahwa data harga saham bank BRI sudah stasioner tetapi pada grafik ACF terjadi penurunan secara perlahan, maka dapat disimpulkan bahwa data harga saham bank BRI belum stasioner dan perlu dilakukan proses diferensing.

\section{Proses diferensing}

Data yang tidak stasioner seringkali didapat dalam kehidupan nyata. Mengingat deret data yang digunakan dalam peramalan ARIMA adalah deret data yang variansi dan rata-ratanya telah stasioner maka untuk data yang tidak stasioner perlu dilakukan pembedaan (differencing) ataupun transformasi. Berdasarkan hasil output menunjukkan nilai koefisien ACF sudah mendekati nol $(0,080)$ pada lag 1 dan pada setiap lag nilai koefisien ACF relatif kecil, bahkan sampai pada lag 30 (0,044). Pola nilai koefisien ACF dengan tingkat diferensing satu menunjukkan bahwa data sudah stasioner.

\section{Identifikasi Model ARIMA}

Dari melihat hasil correlogram ACF dan PACF menunjukkan bahwa pada correlogram ACF terjadi cuts off di lag 1 dan pada correlogram PACF terjadi cuts off di lag 1 dan lag 2, artinya model ARIMA dengan $\operatorname{AR}(p)$ pada tingkat lag 1 dan 2 dan $M A(q)$ pada lag 1 dan pada tingkat diferensing 1 . Sesuai dengan bentuk umum $\operatorname{ARIMA}(p, d, q)$ maka model ARIMA yang akan diestimasi adalah model $\operatorname{ARIMA}(1,1,0), \quad \operatorname{ARIMA}(2,1,0), \quad \operatorname{ARIMA}(0,1,1)$, $\operatorname{ARIMA}(1,1,1)$, dan model ARIMA $(2,1,1)$

\section{Estimasi model ARIMA}

Setelah menetapkan model ARIMA maka model tersebut dapat diestimasi. Model diestimasi untuk memilih model sementara yang akan digunakan dengan melihat nilai AIC dan SIC terkecil. Nilai AIC dan SIC didasarkan pada metode maximum likelihood estimation (MLE). Untuk menghitung nilai AIC dan SIC digunakan rumus sebagai berikut:

$$
A I C=-2 \log (L)+2 m
$$

dengan $L$ adalah maksimum likelihood dan $m$ adalah banyaknya parameter yang akan ditaksir dalam model AR, model MA dan koefisien regresi. Selanjutnya,

$$
S I C=\left(\frac{k}{n}\right) \ln n+\ln \left(\frac{\sum_{i=1}^{n} \hat{u}_{i}^{2}}{n}\right)
$$


dengan $\mathrm{k}$ adalah banyaknya parameter yang diestimasi dalam model regresi, $\mathrm{n}$ adalah jumlah observasi, dan u adalah sisa Fathurahman, 2009). Berikut merupakan rekapitulasi nilai AIC dan SIC hasil estimasi model ARIMA:

Tabel 1. Rekapitulasi AIC dan SIC bank BRI

\begin{tabular}{|c|c|c|}
\hline MODEL & AIC & SIC \\
\hline ARIMA(1,1,0) & 13,48174 & 13,49266 \\
\hline ARIMA(2,1,0) & 13,48033 & 13,49673 \\
\hline ARIMA(0,1,1) & 13,48116 & 13,49207 \\
\hline ARIMA(1,1,1) & 13,48173 & 13,49811 \\
\hline ARIMA(2,1,1) & 13,46449 & 13,48635 \\
\hline
\end{tabular}

Dalam penelitian ini model terbaik yang akan dipilih dilihat dari nilai AIC dan SIC. Berdasarkan hasil rekapitukasi pada tabel 1 menunjukkan bahwa masing-masing model yang memiliki nilai AIC dan SIC yang paling terkecil yaitu model $\operatorname{ARIMA}(2,1,1)$ dimana nilai AIC sebesar 13,46449 dan nilai SIC sebesar 13,48635.

\section{Uji diagnosis model ARIMA}

Model ARIMA yang terpilih kemudian akan diuji apakah menghasilkan residual yang random (white noise) sehingga model tersebut merupakan model yang mampu menjelaskan data dengan baik. Wei (1994) menjelaskan tentang proses white noise bahwa time series $\left\{\varepsilon_{t}\right\}$ dinamakan proses white noise apabila rangkaiannya merupakan variabel acak yang idependen dan berdistribusi identik. Proses white noise dinamakan juga Gaussian jika berdistribusi normal. Untuk selanjutnya, proses $\left\{\varepsilon_{t}\right\}$ adalah proses white noise berdistribusi normal dan memiliki rataan nol (Wei, 1994).

Berdasarkan output yang didapat pada masingmasing lag memiliki nilai probabilitas yang lebih besar dari nilai $\alpha=0,05$, maka dapat disimpulkan bahwa residual yang diestimasi dari model $\operatorname{ARIMA}(2,1,1)$ merupakan residual yang white noise. Identifikasi efek heteroskedastik

Pemodelan time series univariat yang sering digunakan adalah model time series Box-Jenkins, yaitu Autoregressive (AR), Moving Average (MA), dan gabungan kedua model Autoregressive Moving Average (ARMA). Tetapi dalam model tersebut asumsi yang digunakan untuk eror adalah asumsi homoskedastik (variansi sama setiap waktu). Apabila berhubungan dengan data finansial, misalnya tingkat inflansi, harga saham, dan sebagainya, seringkali dijumpai data time series memiliki variansi eror tidak konstan. Salah satu model time series yang mengizinkan adanya heteroskedastik (variansi berubah-ubah untuk setiap waktu t) adalah model Autoregressive Conditional Heteroscedastic (ARCH) (Nainggolan, 2009). Dalam pemodelan GARCH didahului dengan identifikasi apakah data yang diamati mengandung heteroskedastik atau tidak. Untuk hasil ARCH-LM keputusan yang diambil berdasarkan uji hipotesis sebegai berikut:

$H_{0}$ : Tidak ada efek ARCH/GARCH pada bank BRI (homokedastik)

$H_{1}$ : Ada efek ARCH/GARCH pada bank BRI (heteroskedastik)

Berdasarkan uji ARCH-LM harga saham BRI menunjukkan bahwa nilai p-value $<0,05$ artinya tolak $H_{0}$ atau ada efek ARCH-GARCH (heteroskedastik). Melalui hasil pengujian, dapat disimpulkan data harga saham bank BRI pada model $\operatorname{ARIMA}(2,1,1)$ mengandung unsur heteroskedastik, maka akan diestimasi model ARCH-GARCH karena memiliki unsur heteroskedastik.

\subsection{Estimasi model ARCH-GARCH}

Dalam menentukan model ARCH-GARCH dapat dilihat pada correlogram ACF dan PACF. Berdasarkan correlogram ACF dan PACF menunjukkan terjadi cuts off sampai pada lag ke 2, sehingga dapat diduga model GARCH yang akan digunakan yaitu $\operatorname{GARCH}(2,2)$.

Dari hasil output menunjukan bahwa setelah memasukkan unsur GARCH hasil estimasi memberikan nilai AIC dan SIC yang lebih rendah dari sebelumnya pada model $\operatorname{ARIMA}(2,1,1)$. Nilai AIC dan SIC pada model GARCH $(2,2)$ masing-masing sebesar 13,42128 dan 13,47048 lebih rendah dibandingkan nilai AIC dan SIC pada model $\operatorname{ARIMA}(2,1,1)$ masing-masing sebesar 13,46449 dan 13,48635. Hal ini menunjukkan bahwa dalam penggunaan model ARCH-GARCH tepat untuk data yang mengalami heteroskedastik. Berikut merupakan model $\operatorname{ARIMA}(2,1,1)-\operatorname{GARCH}(2,2)$ :

$$
\begin{gathered}
Z_{t}=\phi_{1} Z_{t-1}+\phi_{2} Z_{t-2}+\varepsilon_{t}-\theta_{1} \varepsilon_{t-1} \\
W_{t}=\phi_{1} W_{t-1}+\phi_{2} W_{t-2}+\varepsilon_{t}-\theta_{1} \varepsilon_{t-1}
\end{gathered}
$$

dimana ,

$$
\begin{gathered}
\varepsilon_{t}=\eta_{t} \sqrt{h_{t}} \\
W_{t}=Z_{t}-Z_{t-1}
\end{gathered}
$$

$Z_{t}-Z_{t-1}=\phi_{1}\left(Z_{t-1}-Z_{t-2}\right)+\phi_{2}\left(Z_{t-2}-Z_{t-3}\right)-$

$\theta_{1} \varepsilon_{t-1} Z_{t}=Z_{t-1}+\phi_{1}\left(Z_{t-1}-Z_{t-2}\right)+\phi_{2}\left(Z_{t-2}-Z_{t-3}\right)-$ $\theta_{1} \varepsilon_{t-1} Z_{t}=Z_{t-1}+\left(Z_{t-1}-Z_{t-2}\right)+\phi_{2}\left(Z_{t-2}-Z_{t-3}\right)-$ $\theta_{1} \varepsilon_{t-1} Z_{t}=7,778+0,897 Z_{t-1}-0,011 Z_{t-2}-$ $0,851 \varepsilon_{t-1} h_{t}=15445,69+0,124 \varepsilon_{t-1}^{2}+0,004 \varepsilon_{t-2}^{2}+1,049 h_{t-1}-$ $0,538 h_{t-2}$

Setelah itu, pengujian kembali ARCH-LM apakah data harga saham BRI masih memiliki unsur heteroskedastik atau tidak. Dari hasil pengujian kembali uji ARCH-LM pada model $\operatorname{GARCH}(2,2)$ diketahui bahwa nilai $p$-value $>0,05$. Hal ini menunjukkan bahwa pada model $\operatorname{GARCH}(2,2)$ sudah tidak memiliki unsur heteroskedastik.

\section{Evaluasi model ARIMA-GARCH}

Langkah terakhir ini dilakukan untuk mengevaluasi model ARIMA-GARCH yang telah didapat. Penelitian ini diprediksi untuk periode 1 minggu ke depan. Berikut merupakan hasil prediksi harga penutupan saham BRI: 
Tabel 2. Hasil prediksi harga penutupan saham BBRI

\begin{tabular}{|c|c|c|c|c|c|}
\hline \multirow[t]{2}{*}{ Periode } & \multicolumn{3}{|c|}{ Prediksi } & \multicolumn{2}{|c|}{ Aktual } \\
\hline & BNI & BRI & $\begin{array}{l}\text { Varians } \\
\left(h_{t}\right) \text { BRI }\end{array}$ & BNI & BRI \\
\hline 8 Mei 2017 & 6575,149 & 13963.334 & 100088.9 & 6725 & 14100 \\
\hline 9 Mei 2017 & 6738,349 & 14069.791 & 75283.63 & 6650 & 14000 \\
\hline 10 Mei 2017 & 6648,499 & 13974.298 & 41282.87 & 6575 & 13975 \\
\hline 11 Mei 2017 & 6573,499 & 13935.746 & 18359.86 & 6575 & 13975 \\
\hline 12 Mei 2017 & 6578,449 & 13953.967 & 12637.49 & 6675 & 14025 \\
\hline 15 Mei 2017 & 6684,798 & 14014.427 & 19512.13 & - & - \\
\hline 16 Mei 2017 & 6688,894 & 14013.283 & - & - & - \\
\hline 17 Mei 2017 & 6692,613 & 14020.469 & - & - & - \\
\hline 18 Mei 2017 & 6696,307 & 14034.673 & - & - & - \\
\hline 19 Mei 2017 & 6700 & 14055.257 & - & - & - \\
\hline
\end{tabular}

Hasil perdiksi pada tabel 2 harga penutupan saham BRI pada tanggal 15 Mei 2017 terjadi peningkatan harga saham hingga tanggal 19 Mei 2017. Pada gambar 2 terlihat dari Januari 2014 sampai Mei 2017 data aktual tidak berbeda jauh dengan data hasil prediksi.

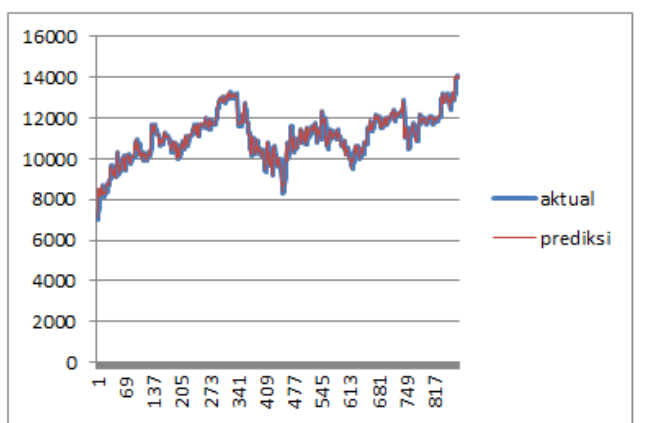

Gambar 2. Plot prediksi harga penutupan saham bank BRI

\section{Uji koefisien determinasi}

Pada penelitian ini, melihat kebaikan model untuk peramalan digunakan koefisien determinasi atau nilai $R^{2}$ (r-squared). Berikut merupakan rumus untuk koefisien determinasi atau $R^{2}$ :

$$
R^{2}=1-\frac{J K S}{J K T}=1-\frac{\sum_{i=1}^{n} \sum\left(y_{i}-\hat{y}_{i}\right)^{2}}{\sum_{i=1}^{n} \sum\left(y_{i}-\bar{y}\right)^{2}}
$$

dimana

$\mathrm{JKS}=$ jumlah kuadrat sisaan

$\mathrm{JKT}=$ jumlah kuadrat total

$y_{i} / y_{a c t}=$ observasi respon ke-i atau data nilai aktual

$\hat{y}_{i} / y_{\text {pred }}=$ data nilai prediksi

Berdasarkan rumus, maka $R^{2}$ nilai yang diperoleh yaitu 0,99916 atau 99,91\%. Sehingga dapat dikatakan model $\operatorname{ARIMA}(2,1,1)-\operatorname{GARCH}(2,2)$ dapat digunakan untuk memprediksi beberapa hari ke depan.

\section{Kesimpulan}

Model time series untuk memprediksi harga saham BRI adalah ARIMA(2,1,1)-GARCH(2,2). Model tersebut dipilih dengan meilihat nilai AIC dan SIC terkecil. Berikut merupakan persamaan yang didapat dari $\operatorname{ARIMA}(2,1,1)-\operatorname{GARCH}(2,2)$ :

$\hat{Z}_{t}=7,778+0,897 Z_{t-1}-0,011 Z_{t-2}-0,851 \varepsilon_{t-1}$ dengan

$h_{t}=15445,69+0,124 \varepsilon_{t-1}^{2}+0,004 \varepsilon_{t-2}^{2}+1,049 h_{t-1}-0,538 h_{t-2}$

Hasil prediksi menyatakan bahwa harga penutupan saham BRI pada tanggal 15 Mei 2017 terjadi peningkatan hingga tanggal 19 Mei 2017. Dengan nilai $R^{2}$ sebesar 0.99916 atau $99,91 \%$ maka model $\operatorname{ARIMA}(2,1,1)$ - $\operatorname{GARCH}(2,2)$ dapat dikatakan baik dalam memprediksi harga saham BRI.

\section{Daftar Pustaka}

Bollerslev, T. 1986. Generalized Autoregressive Conditional Heteroskedasticity. Journal of Econometrics. 31: 307-327.

Box, G.E.P., dan G.M. Jenkins. 1976. Time Series Analysis: Forcesting and Control. Holden-Day. San Fransisco.

Eliyawati W. Y., R. R. Hidayat, dan D.F. Azizah. Penerapan Model GARCH (Generalized Autoregressive Conditional Heteroscedasticity) untuk Menguji Pasar Modal Efisiensi di Indonesia. Jurnal Administrasi Bisnis (JAB).7(2).

Engle, R.F. 1982. Autoregressive Conditional Heteroscedasticity with Estimates of the Variance of United Kingdom Inflation. Journal of Econometrica. 50: 987-1008.

Fathurahman, M. 2009. Pemilihan Model Regresi Terbaik Menggunakan Metode Akaike's Information Criterion dan Schwarz Information Criterion. Jurnal Informatika Mulawarman. 4(3).

Mendome, K., N. Nainggolan, dan J. Kekenusa. 2016. Penerapan Model ARIMA dalam Memprediksi Jumlah Tindak Kriminalitas di Wilayah POLRESTA Manado Provinsi Sulawesi Utara. Jurnal MIPA Unsrat Online. 5(2): 113116.

Nainggolan, N. 2009. Model Time Series Heteroskedastik. Unpad Press. Bandung.

Salmon, S. H. A., N. Nainggolan, dan D. Hatidja. 2015. Pemodelan ARIMA Dalam Prediksi Penumpang Pesawat Terbang Pada Bandara Sam Ratulangi Manado. Jurnal de Cartesian. 4(1).

Wei, W.W.S. 1990. Time Series Analysis: Univariate and Multivariate Method. Addison Wesley Publishing Company, Inc. USA.

https://finance.yahoo.com/quote/BBRI.JK/history?p $=$ BBRI.JK [diakses terakhir tanggal 14 Mei 2017] 